\title{
Climate-related range shifts of Ardisia japonica in the Korean Peninsula: a role of dispersal capacity
}

\author{
Seon Uk Park', Kyung Ah Koo ${ }^{2 *}$, Changwan Seo ${ }^{3}$ and Seungbum Hong ${ }^{4}$
}

\begin{abstract}
Background: Many studies about climate-related range shift of plants have focused on understanding the relationship between climatic factors and plant distributions. However, consideration of adaptation factors, such as dispersal and plant physiological processes, is necessary for a more accurate prediction. This study predicted the future distribution of marlberry (Ardisia japonica), a warm-adapted evergreen broadleaved shrub, under climate change in relation to the dispersal ability that is determined by elapsed time for the first seed production.

Results: We introduced climate change data under four representative concentration pathway (RCP 2.6, 4.5, 6.0, and 8.5) scenarios from five different global circulation models (GCMs) to simulate the future distributions (2041 2060) of marlberry. Using these 20 different climate data, ensemble forecasts were produced by averaging the future distributions of marlberry in order to minimize the model uncertainties. Then, a dispersal-limited function was applied to the ensemble forecast in order to exam the impact of dispersal capacity on future marlberry distributions. In the dispersal-limited function, elapsed time for the first seed production and possible dispersal distances define the dispersal capacity. The results showed that the current suitable habitats of marlberry expanded toward central coast and southern inland area from the current southern and mid-eastern coast area in Korea. However, given the dispersal-limited function, this experiment showed lower expansions to the central coast area and southern inland area.
\end{abstract}

Conclusions: This study well explains the importance of dispersal capacity in the prediction of future marlberry distribution and can be used as basic information in understanding the climate change effects on the future distributions of Ardisia japonica.

Keywords: Ardisia japonica, Climate change, Species distribution model, Dispersal, Korean Peninsula

\section{Background}

The distributions of alpine plants have decreased under global warming (Randin et al. 2009; Koo et al. 2015), and warm-adapted plants expanded or shifted northwards (Nakao et al. 2011, 2014; Yun et al. 2011, 2014; Park et al. 2016, 2016). These changes in plant distribution will cause changes in the structure and functions of forest ecosystems. Therefore, many studies have been conducted to predict changes in plant distribution

\footnotetext{
*Correspondence: Kyungah.koo@gmail.com; kakoo@kei.re.rk

${ }^{2}$ Division of Natural Resources Conservation, Korea Environment Institute,

Bldg B, 370 Sicheong-daero, Sejong 30147, Republic of Korea

Full list of author information is available at the end of the article
}

under climate changes for effective management planning that fits such changes (Díaz et al. 2015).

Most studies on climate-related range shift of plants have focused on understanding the relationship between climatic factors and plant distributions (Thomas et al. 2004). However, for a more accurate prediction of plant future distribution under climate change, a thorough consideration of other factors, such as dispersal and plant physiological responses, is also important (Thomas et al. 2004; Thuiller et al. 2005). Accordingly, the importance of studies considering other factors has been emphasized (Guisan and Thuiller, 2005; Elith and Leathwick 2009). In particular, dispersal is an important mechanism to 
understand how plants adapt to climate changes; as a result, related models, such as Migclim and Biomove, have been developed and applied to the predictions of future plant distributions under climate change (Engler and Guisan 2009; Midgley et al. 2010; Engler et al. 2012).

Species distribution models (SDMs) have been universally used in the predictions of plant distribution and habitat suitability according to climate changes (Guisan and Thuiller 2005; Elith and Leathwick 2009). However, SDMs were criticized for their diverse limitations, such as the lack of ecological knowledge and uncertainties in environmental variables, species distribution models (model uncertainty), and future climate predictions (climate uncertainty) (Barry and Elith, 2006; Wang et al. 2012; Wenger et al. 2013). Diverse ensemble techniques, such as model average and weighted ensemble approach, have been used to minimize model uncertainty of the abovementioned aspects (Thuiller et al. 2009; Wenger et al. 2013). Climate uncertainty was also minimized by applying diverse projections of future climate conditions to the predictions of future plant distribution and then averaging the predictions (Wang et al. 2012).

In the present study, the climate-related range shifts of marlberry (Ardisia japonica (Thunb.) Blume, a warmadapted evergreen broadleaved shrub) were predicted by considering changes in habitat suitability and the dispersal ability. The dispersal ability was considered as a function of dispersal distances and the time when the dispersed seeds grew to bear seeds for the first time. In addition, an ensemble technique that assigned weights to models was utilized to minimize model uncertainty (Thuiller et al. 2009, Wenger et al. 2013), and the ensemble SDM was combined with a dispersal model to consider the dispersal ability. The effects of climate uncertainty on the prediction of future marlberry distribution were minimized by applying diverse climate predictions and averaging the future distributions of marlberry predicted under such diverse climate conditions (Wang et al. 2012).

\section{Methods}

\section{Study species and area}

Marlberry (Ardisia japonica (Thunb.) Blume) is classified into Ardisia japonica family (myrsinaceae) of the angiosperm group. Ardisia japonica family is known to comprise over 1000 species of 35 genera in the whole world, and most of these species are widely distributed in the tropical climatic zones in the Northern and Southern hemispheres (Kang 2012). There are three species of one genera of Ardisia japonica that grow wild mainly in lowlands in islands and southern and western coastal areas in South Korea (Lee 1980). Marlberry is also a warm-adapted evergreen broadleaved shrub that grows mainly in the southern area and coasts (Lee 1980). In addition, this plant is included in the 100 species of the national climate change biomarkers selected for monitoring to understand the effects of climate change on organisms and estimate the vulnerability of organisms to climate change (Ministry of Environment 2010).

The study area, the Korean Peninsula, is located in the north latitudes $32^{\circ} \sim 44^{\circ}$, east longitudes $124^{\circ} \sim 132^{\circ}$, and is surrounded by the sea on three sides. Since it is located on the east of the Eurasian Continent, the precipitation is concentrated on summer due to the influence of summer monsoons (Korea Meteorological Administration 2012). According to Koppen Climate Classification System, temperature humid climates, humid continental climates, and cold with dry winter climates appear regionally (Shin 2006). Alongside with the climatic zones, the Korean Peninsula shows geographical features with contrasts between the west and south coast, having complicated coastlines and many islands, and the east coast, showing simple coastlines (National Geographic Information Institute 2014).

\section{Environmental variables}

Bioclimatic variables were developed according to the spatiotemporal variations of temperature and precipitation, which were climatic conditions that affected living organisms. These variables have been diversely used in previous research on the distribution of and the climate change effects on living organisms (Nix 1986; Hijmans 2004). In the present study, we used the climate data (1960 1990 average) with the resolution of 30 arc second (ca. $1 \mathrm{~km}^{2}$ ) provided by Worldclim (http://www.worldclim.org). Due to the high correlations among the 19 bioclimatic variables, the variables with correlation coefficients above 0.7 were removed through Pearson's correlation tests. As a result, temperature variables bio1 3 and precipitation variables bio12 14 were used to develop marlberry SDMs (see Table 1).

Global circulation models (GCMs) are models to predict future global climates considering the processes of the ocean, atmosphere, and earth surface. Various

Table 1 Bioclimatic variables used for developing species distribution models of marlberry (Ardisia japonica)

\begin{tabular}{ll}
\hline Variable & Description \\
\hline Bio1 & Annual mean temperature \\
Bio2 & Mean diurnal range (mean of monthly (max temp-min temp)) \\
Bio3 & Isothermality (Bio2/Bio7) $\left({ }^{*} 100\right)$ \\
Bio12 & Annual precipitation \\
Bio13 & Precipitation of wettest month \\
Bio14 & Precipitation of driest month \\
\hline
\end{tabular}


institutions throughout the world developed approximately 61 GCMs (Taylor et al. 2012). Since different GCMs consider different processes, each GCM shows a different prediction, which accounts for climate uncertainty. Accordingly, the predictions of species distributions under climate changes will vary with future climates predicted by different GCMs. Therefore, such climate uncertainty should be minimized for more accurate prediction of marlberry distribution, which is important for effective management planning (Kendon et al. 2010). To predict the effects of climate change on the ditribution of Ardisia japonica, we also applied four different greenhouse emission scenarios-namely, representative concentration pathways (RCPs) 2.6, 4.5, 6.0, and 8.5. The details of these scenarios are as follows: in RCP 2.6, greenhouse gas emissions will decrease in the future; in RCP 4.5, quite some of greenhouse gas reduction policies are implemented; in RCP 6.0, greenhouse gas reduction policies are implemented to some extent; and in RCP 8.5, the current greenhouse gas emission trend is maintained. The future climate conditions in 2050 (average of values in 2041 2060) predicted by five GCMs developed in the USA, UK, and Japan and four RCPs (total 20 climate predictions) were used for this study (see Table 2). A total of 20 predictions of marlberry future distributions according to 20 climate predictions were averaged to minimize climate uncertainty that may appear in the predictions of marlberry distributions in 2050 .

\section{Model development and evaluation}

The presence/absence data of marlberry (Ardisia japonica), a dependent variable for SDM development, were obtained from previous studies of Koo (2000), Lee and Yim (2002), and the Korea National Arboretum (2004, 2005, 2006, 2007, 2008, 2009, 2010a, 2010b, 2011). Areas where survey points were adjacent were combined to have one point to maintain the distances between survey points as $>2 \mathrm{~km}$. Complete plant lists were surveyed at each data point;

Table 2 Information of GCMs employed to predict the climate change effects on the future distribution of marlberry (Ardisia japonica)

\begin{tabular}{lll}
\hline GCM & Code & Institution \\
\cline { 2 - 3 } GISS-E2-R & GS & NASA Goddard Institute for Space Studies \\
HadGEM2-AO & HD & Met Office Hadley Centre \\
MRIGEM2-ES & HE & Met Office Hadley Centre \\
MIROC-ESM-CHEM & MG & $\begin{array}{l}\text { Meteorological Research Institute } \\
\text { Japan Agency for Marine-Earth Science } \\
\text { and Technology, Atmosphere and Ocean } \\
\text { Research Institute (University of Tokyo), and } \\
\text { National Institute for Environmental Studies }\end{array}$ \\
\hline
\end{tabular}

therefore, survey points where no marlberry appeared were used as absence data.

To develop SDMs, the environmental variables, bio1 3 and bio12 14, and marlberry presence/absence data at 734 were randomly divided into a training dataset and a test dataset at the ratio of 70:30. To minimize the bias of model results appearing from data division, the abovementioned division process was repeatedly implemented 20 times. SDMs were developed with the training dataset and nine algorithms (Surface Range Envelop (SRE), Classification Tree Analysis (CTA), Random Forest (RF), Generalized Linear Model (GLM), Generalized Boosting Model (GBM), Generalized Additive Model (GAM), Flexible Discriminant Analysis (FDA), Multiple Adaptive Regression Splines (MARS), Artificial Neural Network (ANN)) (Guisan and Zimmermann 2000). The accuracy of each SDM was evaluated with the test dataset. To minimize model uncertainty originating from the individual SDMs, the 108 SDMs that showed True Skill Statistic (TSS) values above 0.7 in the model evaluations were combined using Eq. (1) and produced a TSS-weighted ensemble model (TWE) (Thuiller et al. 2009).

$$
P_{\mathrm{TWE}}=\frac{\sum \mathrm{TSS}_{i} P_{i}}{\sum \mathrm{TSS}_{i}}
$$

Where $i$ is individual SDMs, $P_{i}$ is habitat suitability calculated by individual $i$ SDMs, TSS $i$ is to the TSS value of SDM $i$, and $P_{T W E}$ is the TSS weighted ensemble model of marlberry.

Since SDMs show the probability of species presence, a threshold setting is essential for model verification and identifying the marlberry range. In the marlberry SDMs, the probability of presence where TSS becomes the maximum in individual and ensemble models was set as a threshold for each SDM. Additionally, the accuracy of ensemble forecast of the marlberry distribution was evaluated with the TSS values (Landis and Koch 1977; Pearson 2010).

When predicting suitable habitats according to future environmental changes, SDMs assume species' dispersal ability as being unlimited. However, since species show different dispersal types and limited dispersal distances, assuming unlimited dispersal ability is not realistic (Thomas et al. 2004; Thuiller et al. 2005). Therefore, to solve this problem, the dispersal ability of marlberry was simulated using the MIGCLIM using the Cellular Automata (Engler et al. 2012). The degrees of dispersal of marlberry were calculated with probabilities according to distances using a negative exponential function (see Eq. (2)). The coefficients of the negative exponential 
functions of 0.001 , i.e., the probability of dispersal by animals, and 0.0005 , i.e., the probability of longdistance dispersal, were applied for the dispersal simulations (Vellend et al. 2003). In addition, since the time when plants can produce the first seed can vary with the level of habitat suitability and there is no field experimental information for the dispersal of marlberry, diverse times $(5,10,15$, and 20 years) were assumed for the dispersal simulations. Beginning from the area where marlberry is distributed in the current climate, future expansion of the range was predicted through 60 times of dispersal simulations from 1990 to 2050.

$$
D_{\theta}=\mathrm{e}^{(-\theta d)} \text { for } \theta\{0.001,0.0005\}
$$

where $D_{\theta}$ is the dispersal probabilities by distance according to $\theta$ and $\theta$ is the gradient of negative exponential functions, to which 0.001 and 0.0005 were applied. $d$ indicates the dispersal distance.

\section{Results and discussion}

Prediction of changes in suitable habitats of Ardisia japonica

The suitability of marlberry (Ardisia japonica) habitats in the current climate (1960 1990) was predicted using the TSS-weighted ensemble model, and the

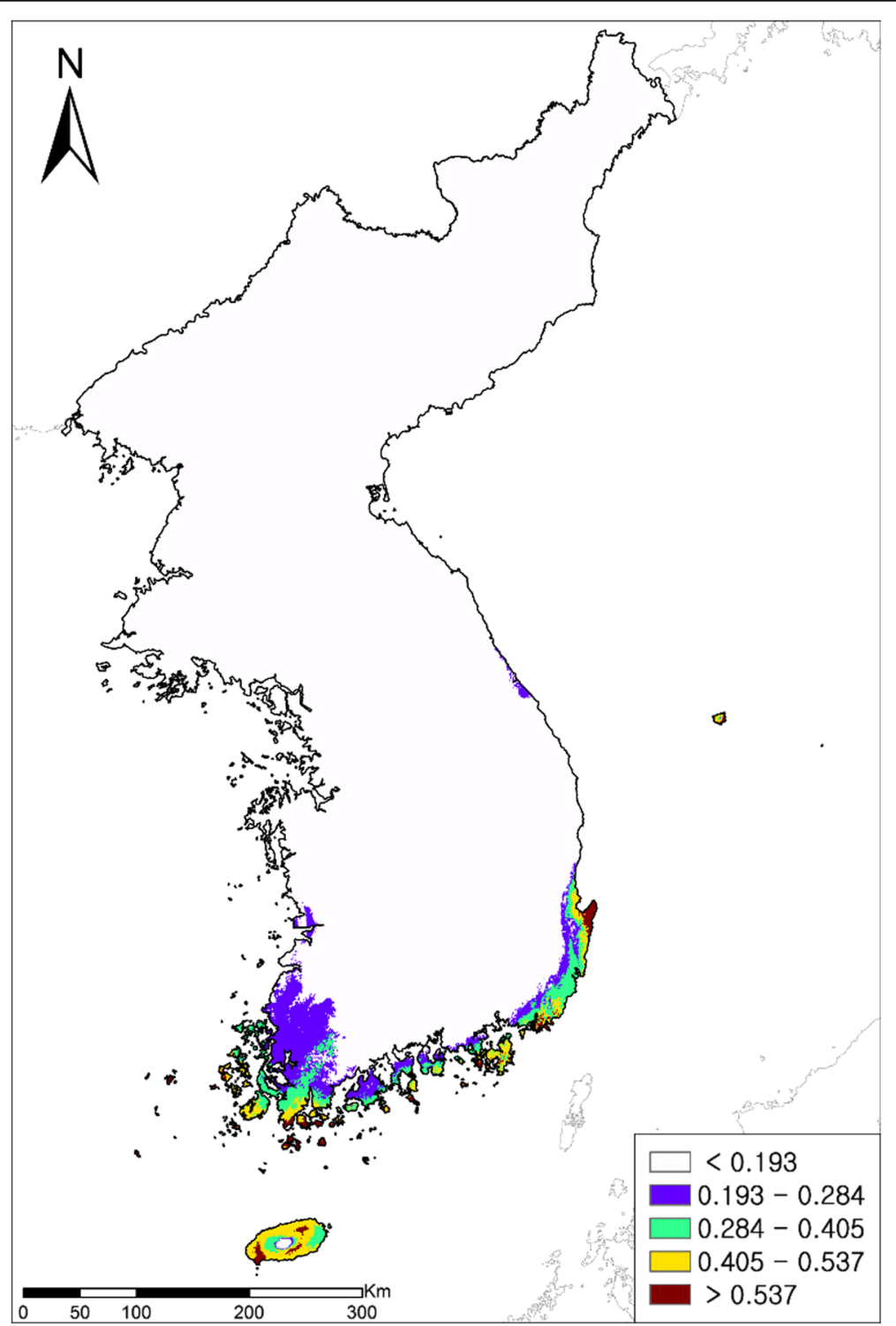

Fig. 1 Ensemble forecast of the probability of marlberry (Ardisia japonica) occurrence in the Korean Peninsula under current climate conditions. The areas with white color $(<0.193)$ on the map explain the absence of marlberry, while those with other colors $(>0.193)$ highlight the presence of marlberry 
predictive power of the model was excellent (TSS $=0.818)$. The threshold indicating the range of marlberry was set to 0.193 , which is where the predictive power of the models becomes the maximum. The area of current suitable habitats is $19,934 \mathrm{~km}^{2}$, consisting of the southern coast area, Jeju-do, excluding Mount Hallasan in the southernmost Korea Peninsula (KP), Jeolla-do inland area in the southern KP, and Ulleungdo and Gangneung in the mid-eastern KP (see Fig. 1). When Gangneung in the mid-eastern KP is excluded, the northern limits of inlands at the east coast and the west coast show similar latitudes. Based on habitat suitability, highly suitable habitats $(>0.537)$ were mainly distributed in the islands in the southern coast and Jeju-do and inland and high latitude habitats showed a low suitability $(0.19-0.284)$. In the future climate, the area of suitable habitats expanded to $29,183 \mathrm{~km}^{2}$ with an expansion by $146 \%$ from the current area. Regionally, the suitable habitats expanded mainly in the mid-eastern KP and Jeolla-do inland areas in the southern KP.

However, the areas expanded in the future show a very low suitability $(0.193-0.284)$. In addition, the areas with a very high suitability $(>0.537)$ were predicted to decrease in the future; most high suitable areas except for some islands in the southern coast disappeared in the future (see Fig. 2). Although suitable habitats appeared in the south coast and inland under

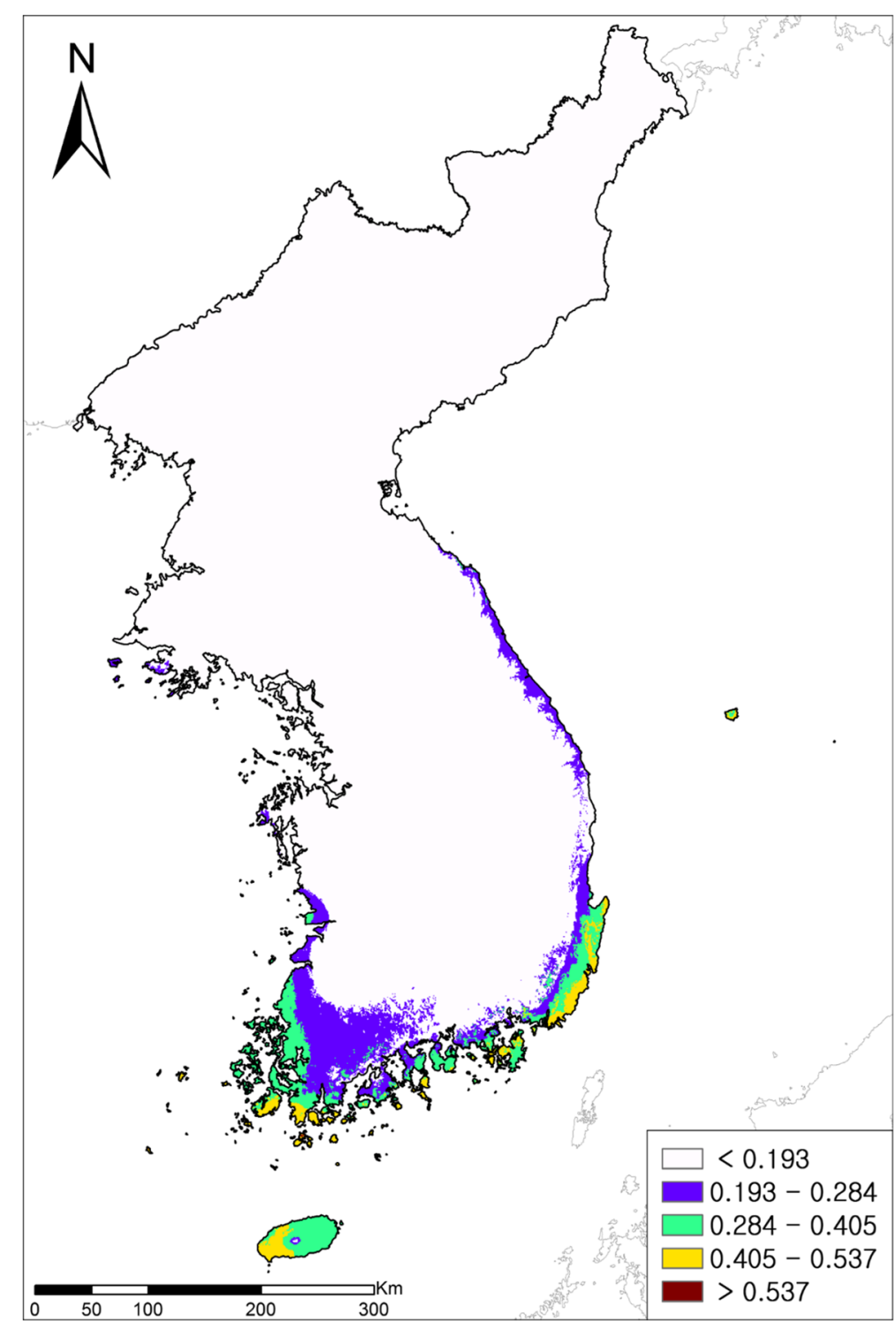

Fig. 2 Ensemble forecast of marlberry (Ardisia japonica) distribution in 2050 under climate change scenarios 
the current climate, the high suitable habitats $(>0.537)$ were Jeju-do coast and lowlands of the south coast, as well as some southern islands. The southern inland area with a large area of suitable habitats showed a low suitability (0.193-0.284). Previous studies predicted that warmtemperate evergreen broadleaf plants would be positively affected by climate changes, such as the expansion of habitats (Nakao et al. 2011, 2014; Yun et al. 2014; Park et al. 2016, 2016). However, in the case of marlberry, the loss of highly suitable habitats may offset the positive effects of climate change.

\section{Prediction of the future distribution of Ardisia japonica under dispersal limitations}

The future suitable habitats of marlberry were predicted by combining the 20 predictions according to 20 climate change scenarios (see Fig. 2). To consider the ability to adapt in the prediction of future marlberry distribution, the areas where marlberry could disperse by 2050 were simulated (see Fig. 3) using the current and future suitable habitats and the dispersal model (Eq. (2)). The current suitable habitats were used as marlberry dispersal starting points, and the future suitable habitats were used as areas where marlberry might disperse. The current distribution on the map explained the suitable habitats of marlberry, and the habitat loss meant the habitat loss of marlberry occurring due to climate changes. The future distribution with dispersal showed the future expansion of marlberry considering the dispersal ability, and the future distribution without dispersal showed the future expansion of marlberry when the dispersal ability was not considered. The suitable habitats were predicted to expand from the Gangneung area to the surroundings in the central coast area through the east coast area, but not in the west coast area. The suitable habitats were predicted to expand in most of Jeollanam-do inland areas in the southern KP (see Fig. 3).

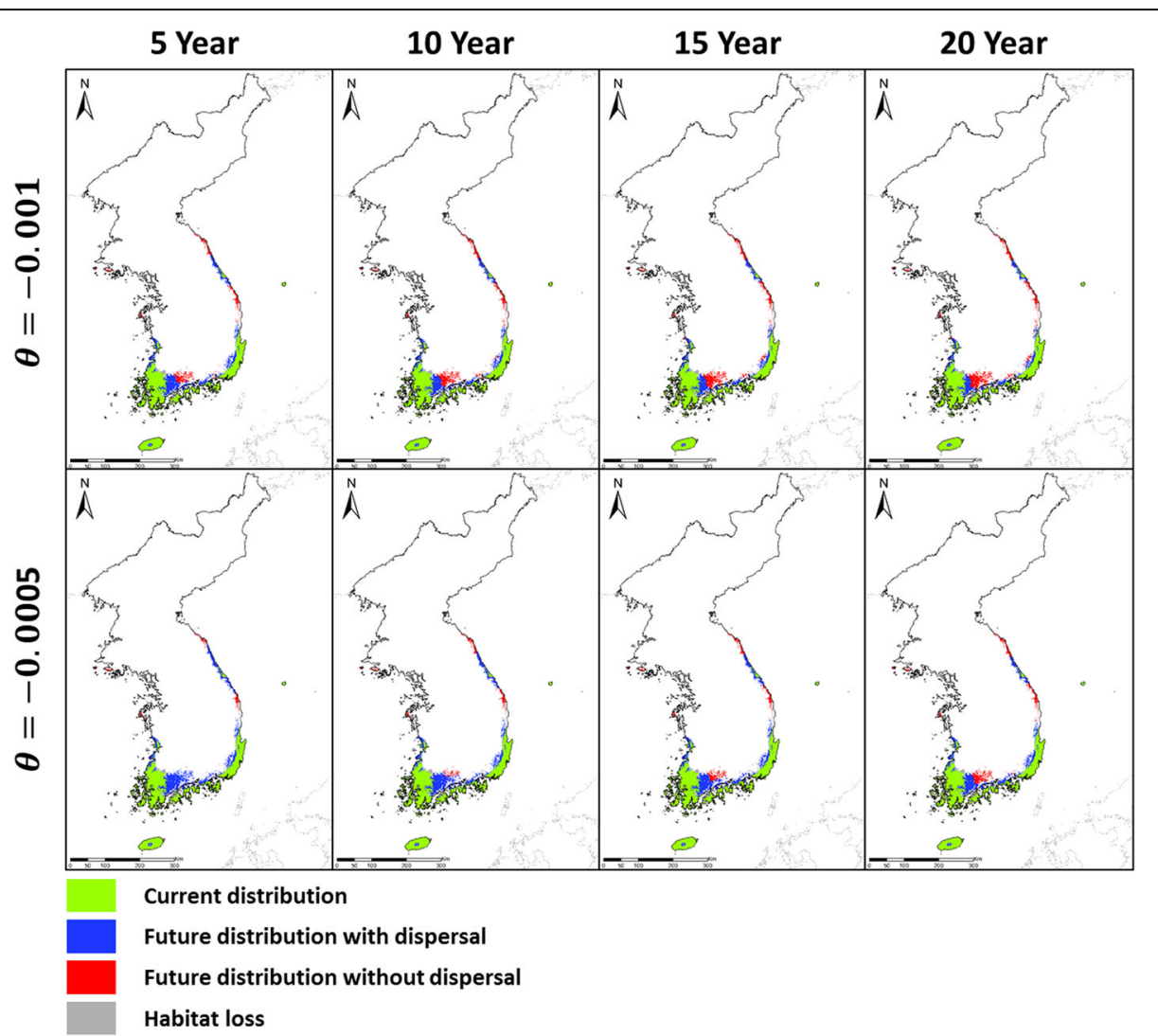

Fig. 3 Ensemble forecast of marlberry (Ardisia japonica) in 2050 under dispersal limitations. The left axis is the coefficient value for the negative exponential equation $(\theta-0.0005,-0.001)$, and the pot axis is the first reproduction year $(5,10,15,20$ years). Current distribution (green color on the map) explains that the distribution of marlberry will stay in the future climate condition. Future distribution with dispersal (blue color on the map) explains the areas where the distribution of marlberry will expand under future climate condition and dispersal limitations. Future distribution without dispersal (red color on the map) explains the areas where the distribution of marlberry will not reach under future climate condition and dispersal limitations. Habitat loss (gray color on the map) explains the areas where marlberry loses its climatic suitable habitats under climate change 
Table 3 The future distributions of marlberry (Ardisia japonica) according to dispersal capacity and the ratio of climatic suitable habitats unlimited by dispersal vs. those restricted by dispersal mechanisms. The dispersal capacity is a function of dispersal distance, coefficients for the negative exponential equation, and the first reproduction year

\begin{tabular}{|c|c|c|c|c|c|c|c|c|}
\hline Coefficient value for the negative exponential equation & -0.001 & & & & -0.000 & & & \\
\hline First reproduction year & 5 & 10 & 15 & 20 & 5 & 10 & 15 & 20 \\
\hline Future distribution area under dispersal limitations $\left(\mathrm{km}^{2}\right)$ & 26,427 & 25,556 & 24,970 & 24,633 & 28,164 & 27,459 & 26,781 & 26,122 \\
\hline Ratio of climatic suitable habitats versus suitable habitats limited by dispersal (\%) & 0.90 & 0.87 & 0.85 & 0.84 & 0.96 & 0.94 & 0.91 & 0.89 \\
\hline
\end{tabular}

The future areas of suitable habitats were differently predicted depending on the coefficient of dispersal functions and the time of the first seed production (see Table 3). When the coefficients of dispersal functions were 0.001 and 0.0005 , the areas of suitable habitats changed within the range of $337 \sim 1794 \mathrm{~km}^{2}$ and $678 \sim 2042 \mathrm{~km}^{2}$ depending on the time of the first seed production. The area of suitable habitats showed the largest value as $28,164 \mathrm{~km}^{2}$ when the coefficient of dispersal function was 0.0005 and the time of the first seed production was 5 years, and the smallest values as $24,633 \mathrm{~km}^{2}$ when the coefficient and the time of first seed production were 0.001 and 20 years, respectively. As comparing the future distribution area predicted under no dispersal limitation, the areas of suitable habitats predicted under dispersal limitations decreased from 16 to $6 \%$.

Although dispersal is a dominant factor to account for plant expansion, it is highly uncertain, as it is affected by diverse conditions, such as growth periods, dispersal types, and topographic conditions. Therefore, for a more accurate prediction of future marlberry distribution according to climate change, topographic factors and ecological characteristics of marlberry should be considered. In addition, such precise prediction will be possible when data established through field and laboratory experiments regarding the range of dispersal and the time for the first seed production become available. Despite these limitations, the present study however showed the importance of considering adaptation ability by showing that the prediction of future distribution of marlberry (Ardisia japonica) varies with dispersal ability. Additionally, the results of the present study provide important basic information for better understanding the effects of climate changes on the evergreen broadleaved forests in the southern part of the Korean Peninsula.

\section{Conclusions}

The present study predicted the future distribution of Ardisia japonica according to climate changes using the TSS-weighted ensemble model and a dispersal function. The current suitable habitats appeared in the southern coast area, Jeju-do, excluding Mount Hallasan in the southernmost KP, Jeolla-do inland area in the southern
$\mathrm{KP}$, and Ulleungdo and Gangneung in the mid-eastern KP. The future suitable habitats were predicted according to five GCMs and four RCP scenarios and then averaged to minimize the effects of climate uncertainty on the predictions. Suitable habitats expanded to the central coast area and the southern inland area under climate change. However, when considering adaptation ability, the expansion of marlberry to the central coast area and the southern inland area was limited. This suggests that even if climates become suitable for marlberry under climate changes, its range expansion will be limited by the dispersal capacity.

\section{Abbreviations}

GCM: Global circulation models; KP: Korean Peninsula; RCP: Representative concentration pathway; SDM: Species distribution model; TSS: True Skill Statistic

\section{Funding}

This work was supported by Korea Environmental Institute, "National Biodiversity Strategy and CBD National Report Project (Project No.: 201700504C77-00)" funded by the Ministry of Environment, the Republic of Korea and the "Climate Change Response Technology Project" of the Ministry of Environment, the Republic of Korea (Project No.: 2014001310009).

\section{Availability of data and materials}

Not applicable.

\section{Authors' contributions}

SUP analyzed the study and wrote the initial draft of the manuscript. CWS and SBH participated in the design of the study and helped to draft the manuscript. KAK participated in the design of the study and wrote the initial draft of the manuscript. All authors read and approved the final manuscript.

Ethics approval and consent to participate

Not applicable.

Consent for publication

Not applicable.

Competing interests

The authors declare that they have no competing interests.

\section{Publisher's note}

Springer Nature remains neutral with regard to jurisdictional claims in published maps and institutional affiliations.

\section{Author details}

${ }^{1}$ Environmental Science \& Ecological Engineering, Korea University, Anam Campus, 145 Anam-ro, Seounbuk-gu, Seoul 02841, Republic of Korea. ${ }^{2}$ Division of Natural Resources Conservation, Korea Environment Institute, Bldg B, 370 Sicheong-daero, Sejong 30147, Republic of Korea. ${ }^{3}$ Division of Ecological Survey and Research, National Institute of Ecology, 2010

Geumgang-ro, Maseo-myeon, Seocheon-gun, Chungnam 33657, Republic of 
Korea. ${ }^{4}$ Division of Ecological Assessment, National Institute of Ecology, Seocheon, Republic of Korea.

\section{Received: 9 July 2017 Accepted: 27 October 2017}

\section{Published online: 22 November 2017}

\section{References}

Barry, S., \& Elith, J. (2006). Error and uncertainty in habitat models. Journal of Applied Ecology, 43(3), 413-423.

Díaz, S., Demissew, S., Carabias, J., Joly, C., Lonsdale, M., Ash, N., Larigauderie, A., Adhikari, J. R., Arico, S., \& Báldi, A. (2015). The IPBES conceptual framework-connecting nature and people. Current Opinion in Environmental Sustainability, 14, 1-16.

Elith, J., \& Leathwick, J. R. (2009). Species distribution models: ecological explanation and prediction across space and time. Annual Review of Ecology, Evolution, and Systematics, 40(1), 677-697.

Engler, R., \& Guisan, A. (2009). MigClim: predicting plant distribution and dispersal in a changing climate. Diversity and Distributions, 15(4), 590-601.

Engler, R., Hordijk, W., \& Guisan, A. (2012). The MIGCLIM R package-seamless integration of dispersal constraints into projections of species distribution models. Ecography, 35(10), 872-878.

Guisan, A., \& Thuiller, W. (2005). Predicting species distribution: offering more than simple habitat models. Ecology Letters, 8(9), 993-1009.

Guisan, A., \& Zimmermann, N. E. (2000). Predictive habitat distribution models in ecology. Ecological Modelling, 135(2), 147-186.

Hijmans RJ, (2004), Arc Macro Language (AML ${ }^{\circledR}$ ) version 2.1 for calculating 19 bioclimatic predictors: Berkeley, Calif, Museum of Vertebrate Zoology, University of California at Berkeley. Available at http://www.worldclim. org/bioclim

Kang BH. (2012). The Korea resource plant. PAJU, Korea Science Information.

Kendon, E. J., Jones, R. G., Kjellström, E., \& Murphy, J. M. (2010). Using and designing GCM-RCM ensemble regional climate projections. Journal of Climate, 23(24), 6485-6503.

Koo KA. (2000). Distribution of evergreen broadleaved trees and climatic factors. KyungHee University.

Koo, K. A., Kong, W., Nibbelink, N. P., Hopkinson, C. S., \& Lee, J. H. (2015). Potential effects of climate change on the distribution of cold-tolerant evergreen broadleaved woody plants in the Korean Peninsula. PLoS One, 10(8), e0134043.

Korea Meteorological Administration. (2012). The climate atlas of Korea. Korea Meteorological Administration, Seoul.

Korea National Arboretum. (2004). Distribution maps of vascular plants of Korean Peninsula I. South coast province. Korea National Arboretum, Pocheon.

Korea National Arboretum. (2005). Distribution maps of vascular plants of Korean Peninsula II. South Province (Jeolla-do \& jirisan). Korea National Arboretum, Pocheon.

Korea National Arboretum. (2006). Distribution maps of vascular plants of Korean Peninsula III. Central \& South Province (Chungcheong-do). Korea National Arboretum, Pocheon.

Korea National Arboretum. (2007). Distribution maps of vascular plants of Korean Peninsula IV. Central \& South Province (Gyeongsangbuk-do). Korea National Arboretum, Pocheon.

Korea National Arboretum. (2008). Distribution maps of vascular plants of Korean Peninsula V. Central Province (Geonggi-do). Korea National Arboretum, Pocheon.

Korea National Arboretum. (2009). Distribution maps of vascular plants of Korean Peninsula VI. Central Province (Gangwon-do). Korea National Arboretum, Pocheon.

Korea National Arboretum. (2010a). Distribution maps of vascular plants of Korean Peninsula VII. South Province (Gyeongsangnam-do) and Ulleung-do Province. Korea National Arboretum, Pocheon.

Korea National Arboretum. (2010b). Distribution maps of vascular plants of Korean Peninsula VII. Jeju-do Province. Korea National Arboretum, Pocheon.

Korea National Arboretum. (2011). Distribution maps of vascular plants of Korean Peninsula IX. West \& South coast Province. Korea National Arboretum, Pocheon.

Landis, J. R., \& Koch, G. G. (1977). The measurement of observer agreement for categorical data. Biometrics, 159-174.

Lee, T. B. (1980). Flora of korea. Hyangmunsa: Seoul.

Lee, W. C., \& Yim, Y. (2002). Plant geography with special reference to Korea. Chuncheon: Kangwon National University press.
Midgley, G. F., Davies, I. D., Albert, C. H., Altwegg, R., Hannah, L., Hughes, G. O., O'Halloran, L. R., Seo, C., Thorne, J. H., \& Thuiller, W. (2010). BioMove-an integrated platform simulating the dynamic response of species to environmental change. Ecography, 33(3), 612-616.

Ministry of Environment. (2010). 100 climate-sensitive biological indicator species. Nakao, K., Higa, M., Tsuyama, I., Lin, C., Sun, S., Lin, J., Chiou, C., Chen, T., Matsui, T., \& Tanaka, N. (2014). Changes in the potential habitats of 10 dominant evergreen broad-leaved tree species in the Taiwan-Japan archipelago. Plant Ecology, 215(6), 639-650.

Nakao, K., Matsui, T., Horikawa, M., Tsuyama, I., \& Tanaka, N. (2011). Assessing the impact of land use and climate change on the evergreen broad-leaved species of quercus acuta in japan. Plant Ecology, 212(2), 229-243.

National Geographic Information Institute. (2014). The national atlas of Korea 1st edition, Suwon, HumanCultureArirang.

Nix, H. A. (1986). A biogeographic analysis of Australian elapid snakes. Atlas of elapid snakes of Australia, 7, 4-15.

Park, S. U., Koo, K. A., \& Kong, W. (2016). Potential impact of climate change on distribution of warm temperate evergreen broad-leaved trees in the Korean Peninsula. Journal of the Korean Geographical Society, 51(2), 201-217.

Park, S. U., Koo, K. A., Seo, C., \& Kong, W.-S. (2016). Potential impact of climate change on distribution of Hedera rhombea in the Korean Peninsula. Journal of Climate Change Research, 7(3), 325-334.

Pearson, R. G. (2010). Species' distribution modeling for conservation educators and practitioners. Lessons in Conservation, 3, 54-89.

Randin, C. F., Engler, R., Normand, S., Zappa, M., Zimmermann, N. E., Pearman, P. B., Vittoz, P., Thuiller, W., \& Guisan, A. (2009). Climate change and plant distribution: local models predict high-elevation persistence. Global Change Biology, 15(6), 1557-1569.

Shin SC. (2006). Research in the climate classification by koppen system in South Korea. Kyungpook Nation University.

Taylor, K. E., Stouffer, R. J., \& Meehl, G. A. (2012). An overview of CMIP5 and the experiment design. Bulletin of the American Meteorological Society, 93(4), 485-498.

Thomas, C. D., Cameron, A., Green, R. E., Bakkenes, M., Beaumont, L. J., Collingham, Y. C., Erasmus, B. F., De Siqueira, M. F., Grainger, A., \& Hannah, L. (2004). Extinction risk from climate change. Nature, 427(6970), 145-148.

Thuiller, W., Lafourcade, B., Engler, R., \& Araújo, M. B. (2009). BIOMOD-a platform for ensemble forecasting of species distributions. Ecography, 32(3), 369-373.

Thuiller W., Lavorel S., Araujo MB., Sykes MT., \& Prentice IC. (2005). Climate change threats to plant diversity in Europe. Proceedings of the National Academy of Sciences of the United States of America 102(23), 8245-8250.

Vellend, M., Myers, J. A., Gardescu, S., \& Marks, P. L. (2003). Dispersal of Trillium seeds by deer: implications for long-distance migration of forest herbs. Ecology, 84(4), 1067-1072.

Wang, T., Campbell, E. M., O’Neill, G. A., \& Aitken, S. N. (2012). Projecting future distributions of ecosystem climate niches: uncertainties and management applications. Forest Ecology and Management, 279, 128-140.

Wenger, S. J., Som, N. A., Dauwalter, D. C., Isaak, D. J., Neville, H. M., Luce, C. H., Dunham, J. B., Young, M. K., Fausch, K. D., \& Rieman, B. E. (2013). Probabilistic accounting of uncertainty in forecasts of species distributions under climate change. Global Change Biology, 19(11), 3343-3354.

Yun, J., Nakao, K., Tsuyama, I., Higa, M., Matsui, T., Park, C., Lee, B., \& Tanaka, N. (2014). Does future climate change facilitate expansion of evergreen broadleaved tree species in the human-disturbed landscape of the Korean Peninsula? Implication for monitoring design of the impact assessment. Journal of Forest Research, 19(1), 174-183.

Yun, J. H., Katsuhiro, N., Park, C. H., Lee, B. Y., \& Oh, K. H. (2011). Change prediction for potential habitats of warm-temperate evergreen broad leaved trees in Korea by climate change. Korean Journal of Environment and Ecology, 25(4), 590-600. 